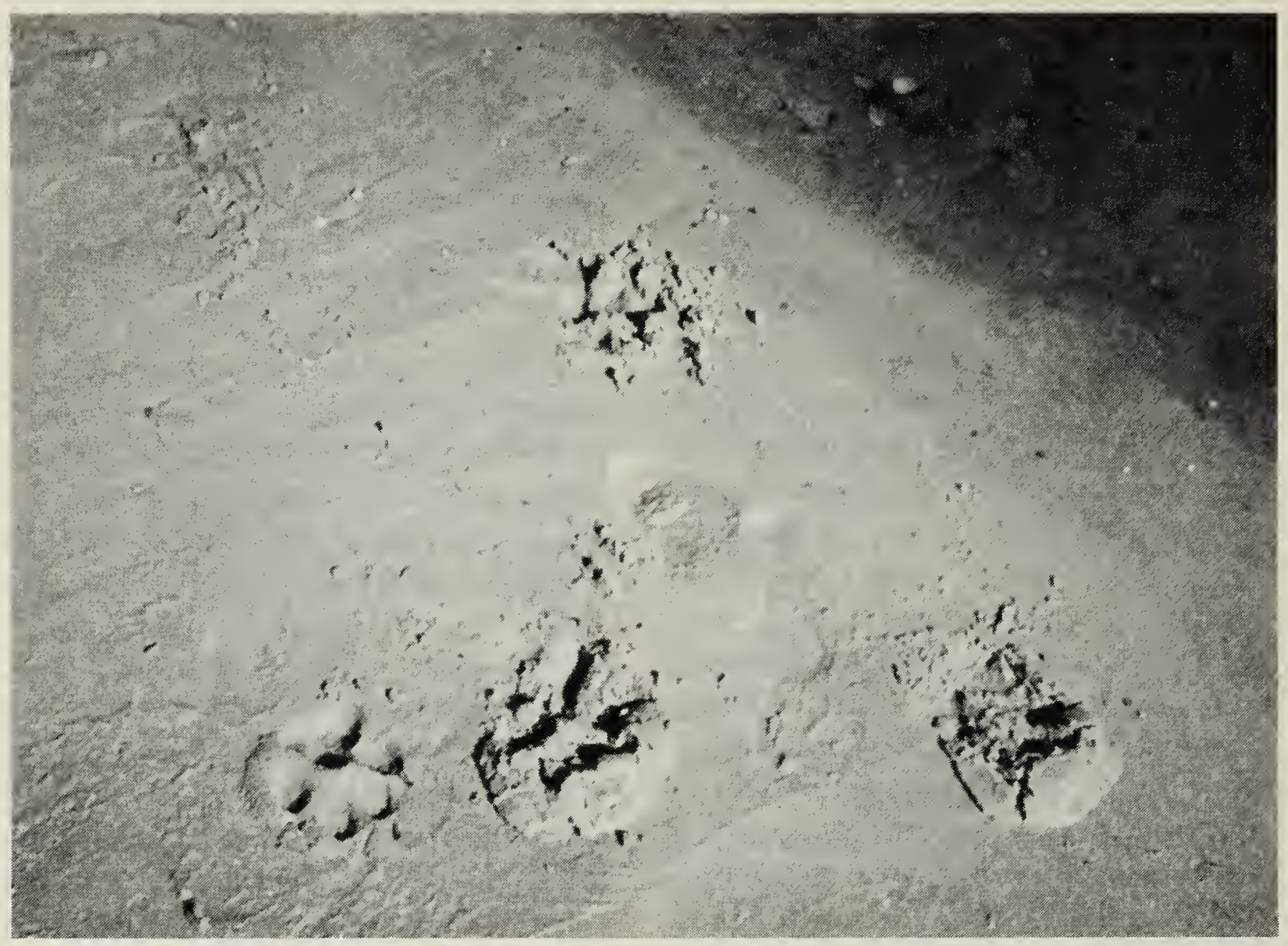

Wolf tracks, Mud Creek, P.A.N.P.

Stuart Dechka

\title{
BATS AND WEASELS
}

The following are a few observations on bats and weasels made in 1991.

\section{Long-tailed Weasels About 7:00} a.m. on 5 July, while driving slowly on a road across a slough $(5 \mathrm{~km}$ northeast of Saskatoon), I saw the heads of several small animals in the grass at the edge of the gravel. They disappeared. I stopped, backed up and waited. In a few minutes, they ran slowly across the road about 100 $\mathrm{m}$ ahead of the car. It was an amazing sight - nine long brown and white bodies, nine long black-tipped tails and 36 short legs in two bunches. They were large weasels - much longer than
Richardson's Ground Squirrels. I was too busy counting to notice whether there was any difference in size within the group.

Bats On 15 August, about 7:45 a.m., while getting out of the car to do some birding at the old Sanatorium site in Saskatoon, I saw two Merlins chasing - or following - a bat (maybe half their size) out of the park. The observation probably lasted four or five seconds before all three disappeared over a building. I doubt that the falcons caught the bat because they were back in the park within two or three minutes. - Bernie Gollop, 2202 York Avenue, Saskatoon, Saskatchewan. S7J 1J1 